\title{
Cara Pengasuhan Anak Sebelum Ditegakkan Diagnosis Gangguan Perkembangan Sistem Reproduksi 46,XY
}

\author{
Nanis S. Marzuki, Lita P. Suciati, Chrysantine Paramayuda, Hannie D. Kartapradja \\ Lembaga Biologi Molekular Eijkman, Jakarta
}

\begin{abstract}
Latar belakang. Gangguan perkembangan sistem reproduksi 46,XY (GPSR 46,XY) bermanifestasi klinis beranekaragam, sehingga dapat dibesarkan sebagai anak laki-laki atau perempuan.

Tujuan. Melihat sebaran cara pengasuhan individu dengan GPSR 46,XY dan dihubungkan dengan kemungkinan diagnosisnya.

Metode. Penelitian deskriptif retrospektif dengan subyek GPSR yang dirujuk untuk analisis kromosom pada tahun 2009-2010 dan hasil analisis kromosom 46,XY.

Hasil. Tujuh puluh pasien GPSR 46,XY dianalisis, dan ditemukan 45 dibesarkan sebagai laki-laki, 22 kasus dibesarkan sebagai perempuan, dan 3 kasus belum ditentukan cara pengasuhan jendernya. Sebagian besar pasien dirujuk pada usia antara $>3$ bulan-8 tahun, (32/70) pasien, dan 12 pasien dirujuk setelah usia 18 tahun. Alasan pasien dirujuk untuk analisis kromosom terutama adalah genitalia ambigu (44/70 kasus).

Kesimpulan. Dengan pendekatan diagnosis yang tepat pada individu GPSR 46,XY orangtua dapat diarahkan untuk mengasuh jender yang sesuai. Untuk itu sangat diperlukan pemeriksaan klinis yang teliti. Sari

Pediatri 2012;13(6):391-96.
\end{abstract}

Kata kunci: sistem reproduksi, jender

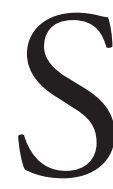

ejak dilahirkan jenis kelamin merupakan suatu faktor utama untuk menentukan pola asuh bagi orangtua untuk membesarkan anaknya sebagai laki-laki atau perempuan. Untuk menentukan hal tersebut, keputusan sangat dipengaruhi oleh budaya dan masyarakat lingkungan Pernyataan jenis kelamin

Alamat korespondensi:

Dr. Nanis S Marzuki, Sp.A. Lembaga Biologi Molekular Eijkman. Jl. Diponegoro 69, Jakarta Pusat. Telp. (021) 3917131 pertama kali oleh penolong persalinan akan menentukan identitas jender seseorang. Demikian pula untuk anak yang lahir dengan genitalia ambigu, keadaan tersebut dapat diketahui sejak lahir atau kemudian. ${ }^{1}$

Genitalia ambigu merupakan paradigma utama pada kondisi disorders of sex development (DSD) atau gangguan perkembangan sistem reproduksi (GPSR). Istilah GPSR merupakan istilah yang mencakup sekelompok kelainan bawaan dengan gangguan perkembangan kromosom, gonad atau anatomi jenis kelamin atipik, menggantikan istilah sebelumnya 
'interseks'. ${ }^{2-4}$ Genitalia ambigu terjadi pada 1: 4.500 kelahiran, sedangkan angka kejadian yang pasti belum diketahui. ${ }^{5,6}$ Kategori GPSR dibagi menjadi tiga berdasarkan hasil analisis kromosom, yaitu GPSR kromosom seks, GPSR 46,XX, dan GPSR 46,XY. ${ }^{2,3}$

Gangguan perkembangan sistem reproduksi GPSR 46,XY dapat bermanifestasi klinis sebagai pria maupun wanita, selain genitalia ambigu dan dapat dijumpai di sepanjang usia seseorang. Dengan keanekaragaman fenotip ini seorang anak dengan GPSR 46,XY dapat dibesarkan sebagai anak laki-laki ataupun perempuan. ${ }^{17,8}$ Dengan pendekatan diagnosis yang tepat pada individu GPSR 46,XY orangtua dapat diarahkan untuk mengasuh jender yang sesuai, sehingga dapat meringankan efek psikososial dan psikoseksual yang dapat timbul di kemudian hari, karena ketidaktepatan dalam pengasuhan jender., ${ }^{6,8}$ Dokter anak yang menghadapi kasus DSD perlu memberi penjelasan yang memadai pada pasien, orangtua dan keluarga pasien. Untuk itu perlu diagnosis yang tepat memerlukan pemeriksaan klinis, laboratorium, hormonal, radiologis, atau bahkan dengan eksplorasi bedah. Tidak semua pasien dapat menjalani hal tersebut, karena kendala biaya atau sarana yang tidak memungkinkan. Dalam hal ini diperlukan cara lain untuk mendiagnosis agar lebih terarah dengan hanya berdasar pada pemeriksaan klinis, dan analisis kromosom.

Penelitian ini bertujuan untuk mengetahui sebaran cara pengasuhan jender individu dengan GPSR 46,XY dan dihubungkan dengan kemungkinan diagnosisnya.

\section{Metode}

Penelitian deskriptif retrospektif dengan subyek penelitian pasien GPSR yang dirujuk ke klinik lembaga Eijkman untuk analisis kromosom pada tahun 2009-
2010, dan hasil analisis kromosom yang ditemukan 46,XY tanpa mosaicism. Data cara pengasuhan jender, alasan klinis dirujuk, dan usia saat dirujuk dipresentasikan dalam bentuk tabel dan dianalisis. Berdasarkan indikasi beberapa pasien dilakukan pemeriksaan gen SRY sesuai dengan protokol yang sudah pernah dilaporkan. ${ }^{9}$

\section{Hasil}

Selama periode tahun 2009 sampai dengan 2010 didapatkan 70 pasien GPSR yang dirujuk ke klinik kami untuk pemeriksaan analisis kromosom dan dideteksi hasil kromosom adalah 46,XY. Tabel 1 menggambarkan sebaran cara pengasuhan jender menurut usia saat dirujuk.

Di antara 70 kasus GPSR 46,XY yang dirujuk, 45 kasus dibesarkan sebagai laki-laki, 22 sebagai perempuan, dan 3 kasus belum ditentukan jenis asuhan jender. Sebagian besar kasus dirujuk pada usia 3 bulan- 8 tahun (32 kasus), dan di usia pubertas 8 tahun-14 tahun (13 kasus). Dijumpai 16 kasus yang dirujuk setelah usia pubertas, yaitu 4 di usia 14 tahun18 tahun, dan 12 di usia dewasa $>18$ tahun. Sebagian besar (12 kasus) di antara 16 kasus dibesarkan sebagai perempuan.

Pada Tabel 2 dan 3 tertera proporsi terbesar alasan merujuk adalah genitalia ambigu (44 kasus), dan 9 di antaranya dibesarkan sebagai perempuan. Anak GPSR 46,XY yang dibesarkan sebagai perempuan dan dirujuk di usia $>14$ tahun sebagian besar dirujuk karena amenore primer ( 5 kasus). Empat kasus GPSR $46, \mathrm{XY}$ berusia $>14$ tahun dan diasuh sebagai laki-laki dirujuk karena diduga mengalami Sindrom Kallman atau Sindrom Kleinefelter. Pada 7 kasus dilakukan pemeriksaan gen SRY dengan hasil positif terdapat pada 7 kasus yang diasuh sebagai perempuan. Lima dari

Tabel 1. Sebaran cara pengasuhan jender individu GPSR 46,XY

\begin{tabular}{lcccc}
\hline Usia saat dirujuk & $\begin{array}{c}\text { Laki-laki } \\
(\mathrm{n})\end{array}$ & $\begin{array}{c}\text { Perempuan } \\
(\mathrm{n})\end{array}$ & $\begin{array}{c}\text { Belum ditentukan/ } \\
\text { tidak diketahui }(\mathrm{n})\end{array}$ & Jumlah \\
\hline Bulan dirujuk & 5 & 1 & 3 & 9 \\
$>3$ bulan-8 tahun & 26 & 6 & 0 & 32 \\
$>8$ tahun-14 tahun & 10 & 3 & 0 & 13 \\
$>14$ tahun-18 tahun & 2 & 2 & 0 & 4 \\
$>18$ tahun & 2 & 10 & 0 & 12 \\
\hline Jumlah & 45 & 22 & 3 & 70 \\
\hline
\end{tabular}


Nanis S Marzuki dkk: Cara pengasuhan anak sebelum ditegakkan diagnosis gangguan sistem reproduksi 46,xy

Tabel 2. Sebaran cara pengasuhan menurut pemeriksaan gen SRY pada anak laki-laki

\begin{tabular}{lccccc}
\hline \multirow{2}{*}{ Alasan rujukan } & \multicolumn{4}{c}{ Usia saat rujukan (n) } & Tidak diketahui \\
\cline { 2 - 6 } & $0-3$ bln & $>3$ bln-8 thn & $>8-14$ thn & $>14$ thn & $0-3$ bulan \\
\hline $\begin{array}{l}\text { Ambigus genitalia } \\
\text { Amenore primer }\end{array}$ & 5 & 20 & 6 & 1 & 3 \\
$\begin{array}{l}\text { Pubertas terlambat } \\
\text { Hipospadia atau mikropenis }\end{array}$ & & 5 & 1 & 1 & \\
$\begin{array}{l}\text { Tersangka Sindrom Kallman } \\
\text { Tersangka Sindrom Kleinefelter }\end{array}$ & 1 & 3 & 1 & \\
$\begin{array}{l}\text { Perawakan pendek } \\
\text { Tidak diketahui }\end{array}$ & & & & & \\
\hline
\end{tabular}

Tabel 3. Sebaran cara pengasuhan menurut pemeriksaan gen SRY pada anak perempuan

\begin{tabular}{lccccc}
\hline \multirow{2}{*}{ Alasan rujukan } & \multicolumn{3}{c}{ Usia saat rujukan } & Tidak diketahui \\
\cline { 2 - 5 } & $0-3$ bln & $>3$ bln-8 thn & $>8-14$ thn & $>14$ thn & $0-3$ bulan \\
\hline Ambigus genitalia & & $5^{*}$ & 1 & 3 & 3 \\
Amenore primer & & & & $5^{* *}$ & \\
$\begin{array}{l}\text { Pubertas terlambat } \\
\text { Hipospadia atau mikropenis }\end{array}$ & 1 & & & & \\
Tersangka Sindrom Kallman & & & & & \\
Tersangka Sindrom Kleinefelter & & & & & \\
Perawakan pendek & & & 2 & 4 & \\
Tidak diketahui & & 1 & & & \\
\hline
\end{tabular}

Catatan:*: jumlah kasus dengan SRY (+) 2; **: jumlah kasus dengan SRY (+) 5

7 kasus tersebut diasuh sebagai perempuan dan dirujuk di atas usia 14 tahun dengan amenore primer.

\section{Pembahasan}

Tata laksana awal GPSR tergantung pada kepastian diagnosis, meskipun diketahui bahwa hal ini sulit dicapai pada sebagian besar kasus, mengingat $>50 \%$ kasus GPSR,XY diagnosis pasti tidak dapat ditegakkan. Dianjurkan pada semua bayi baru lahir dengan genitalia ambigu sebaiknya segera ditentukan jendernya, setelah dievaluasi oleh tim ahli multidisiplin. Diskusi dengan orangtua pada saat awal harus dilakukan secara terbuka, dan diusahakan partisipasi orangtua dalam penentuan keputusan. ${ }^{2-4}$

Dalam menghadapi seorang anak terutama bayi baru lahir dengan genitalia ambigu, atau kemungkinan mengalami GPSR, pada umumnya ada dorongan dan keinginan untuk segera membuat diagnosis pasti atau penentuan jender. Keadaan tersebut muncul akibat tekanan kultural, yaitu kebiasaan mengumumkan pada teman-teman, dan keluarga serta sanak saudara apakah si bayi 'laki-laki' atau 'perempuan'.,5 Namun penentuan diagnosis dan jender pada kasus GPSR sangatlah kompleks dan membutuhkan waktu, untuk menghindari membuat keputusan dini yang salah dan tidak berdasar sehingga tidak sesuai dengan diagnosis sebenarnya. ${ }^{3,4}$

Seseorang yang secara genetik laki-laki, misalnya pada GPSR 46,XY, dapat mempunyai klinis genitalia eksterna perempuan, genitalia ambigu, atau laki-laki, termasuk juga laki-laki dengan mikropenis (panjang penis $<2,5$ SD untuk umur). ${ }^{1,4}$ Dalam penelitian kami ini dari 70 pasien dengan GPSR 46,XY didapatkan 45 dibesarkan sebagai laki-laki, 22 dibesarkan sebagai perempuan, dan 3 masih belum ditentukan jenis kelaminnya. Sebagian besar kasus-kasus tersebut dirujuk di usia bayi dan anak ( $>3$ bulan-8 tahun), yaitu sebanyak 32/70 kasus (Tabel 1). Penelitian dari Turki ${ }^{1}$ juga mendapatkan sebagian besar pasien GPSR XY dirujuk setelah berusia 5 tahun (31/56 kasus) namun jumlah kasus yang dibesarkan sebagai laki-laki maupun perempuan sama. Pada penelitian 
tersebut anak yang dibesarkan sebagai laki-laki dirujuk lebih dini (17/25) daripada yang dibesarkan sebagai perempuan. Sedangkan penelitian Reiner di Oklahoma ${ }^{10}$ mendapatkan dari 73 kasus GPSR dengan kromosom Y pada genome, 60 diantaranya dibesarkan sebagai perempuan dan 26/60 kasus tersebut mengakui perempuan sebagai identitas jendernya. Perbedaan hasil ini kemungkinan disebabkan oleh perbedaan dalam subyek penelitian, Reiner mengikutkan individu dengan mixed gonadal dysgenesis.

Hal yang perlu mendapat perhatian adalah 12 dari 70 kasus $(17,1 \%)$ dirujuk di atas usia 18 tahun dan sebagian besar kasus tersebut (10/12) dibesarkan sebagai perempuan. Manifestasi klinis GPSR 46,XY dapat ditemukan pada usia bayi, anak-anak, pubertas, bahkan di usia dewasa. Namun ada beberapa kondisi yang perlu dicurigai mengalami GPSR 46,XY, seperti 1) Manifestasi dini, yaitu genitalia ambigu pada neonatus, testis tak teraba pada 'bayi' laki-laki, penonjolan/ tumor di daerah inguinal pada anak 'perempuan', hipospadia berat, klitoromegali; 2) Manifestasi lambat, yaitu virilisasi saat pubertas pada anak perempuan, dan amenore primer, serta ginekomastia, dan infertilitas pada laki-laki. ${ }^{4,5}$

Sebagian besar kasus dirujuk karena genitalia ambigu (44/70 kasus) dan hanya 8 dari 44 kasus dideteksi atau dirujuk untuk diagnosis di usia 0-3 bulan. Penelitian Al-Mutair dkk ${ }^{11}$ di Arab Saudi mendapatkan 63/120 kasus genitalia ambigu disebabkan oleh penyakit endokrin dan 24/63 kasus tersebut merupakan pasien GPSR 46,XY. Dengan memperhatikan keadaan klinis, 10 pasien GPSR 46,XY yang dirujuk di usia $>18$ tahun dan dibesarkan sebagai perempuan (Tabel 1), dan juga 36 kasus dengan genitalia ambigu (Tabel 2) mungkin dapat dideteksi lebih dini (di usia anak) dengan anamnesis dan pemeriksaan klinis lebih teliti. Dalam hal ini anamnesis dan pemeriksaan status pubertas serta genitalia sangat penting dalam rangkaian pemeriksaan klinis GPSR 46,XY. ${ }^{3,12}$ Selain itu kemungkinan keterlambatan diagnosis karena faktor ketidakwaspadaan atau penundaan dari pihak orangtua atau pasien sendiri.

Keterlambatan diagnosis akan sangat mempengaruhi kehidupan pasien, yaitu dalam kehidupan psikososial maupun kualitas hidup. Hal ini banyak dilaporkan pada individu dengan GPSR 46,XY yang melakukan peninjauan kembali penentuan jender, dan kemudian berkeputusan mengubah. ${ }^{7,8,13}$ Tentu saja mengubah jender tidaklah mudah karena melalui proses yang panjang dengan segala konsekuensi psikososial, psikoseksual, dan ekonomi, terutama apabila koreksi bedah harus dilakukan. ${ }^{3,4,6}$ Melalui diagnosis yang tepat oleh tim ahli multidisiplin diharapkan proses penggantian atau penggantian jender di kemudian hari dapat dihindari. Warne $\mathrm{dkk}^{6}$ mengajukan 6 prinsip dasar dalam mengangani anak dengan GPSR, yaitu, 1) Meminimalkan risiko fisis pada anak, 2) Meminimalkan risiko psikososial pada anak, 3) Menjaga potensi untuk fertilitas, 4) Menjaga dan mengusahakan kemampuan untuk melakukan hubungan seksual yang memuaskan, 5) Membiarkan beberapa kesempatan terbuka untuk masa depan anak, 6) Menghargai harapan dan kepercayaan orangtua.

Terdapat berbagai macam alur dalam menegakkan diagnosis GPSR, namun dalam pelaksanaan tidak dapat diseragamkan untuk masing-masing kasus. Secara garis besar terdapat beberapa hal yang dapat dipakai acuan untuk mengarahkan diagnosis, seperti yang dijelaskan oleh Wisniewski $\mathrm{dkk}^{8}$ (Tabel 3).

Dengan menggunakan Tabel 4 dan pemeriksaan klinis yang teliti, data yang ditampilkan pada Tabel 2 dan 3 dapat dianalisis dan diperkirakan diagnosis pasien. Hal tersebut tentu saja diharapkan dapat membantu klinisi apabila pemeriksaan lengkap tidak dapat dilakukan.

Tabel 4. Etiologi GPSR 46,XY menurut gambaran klinis genitalia eksterna

\begin{tabular}{|c|c|c|}
\hline Fenotip genitalia perempuan & Fenotip genitalia ambigu & Mikropenis \\
\hline Sindrom androgen insensitif komplit & Sindrom androgen insensitif parsial & Panhipopituitarism \\
\hline Disgenesis gonad komplit (Sindrom Swyer) & Disgenesis gonad parsial & Hipogonadotropik hipogonadism \\
\hline $\begin{array}{l}\text { Gangguan biosintesis testosteron* komplit } \\
\text { Aplasia sel Leydig } \\
\text { Defek reseptor LH komplit }\end{array}$ & $\begin{array}{l}\text { Gangguan biosintesis testosteron* parsial } \\
\text { Idiopatik }\end{array}$ & Idiopatik \\
\hline
\end{tabular}

Dikutip dari: Wisniewski AB, dkk.8 Long-term psychosexual development in genetic males affected by disorders of dex development (46,XY DSD) reared male or female. Curr Ped Rev 2008. *Gangguan biosintesis testosteron: StAR, P450scc, 3ßHSDII, 17 $\beta$-HSD-3; LH: Luteinizing Hormone. 
Sebagai contoh, lima pasien GPSR 46,XY perempuan yang dirujuk setelah berusia 14 tahun dengan amenore primer dapat mengalami sindrom Swyer, sindrom androgen insensitif komplit, gangguan biosintetik testosteron komplit, defek reseptor LH komplit, atau aplasia sel Leydig. ${ }^{4,8}$ Kelima kondisi ini dapat dibedakan secara klinis. ${ }^{7,8,12}$ Gangguan biosintetik testosteron yang dapat menyebabkan fenotip perempuan, yaitu defek enzim StAR atau P450scc bermanifestasi di masa neonatus dengan gangguan elektrolit dan cairan yang berat dan seringkali mengancam nyawa. Defek enzim $3 \beta$ HSDII dan $17 \beta-$ HSD-3 akan mengalami virilisasi di masa pubertas, karena efek androgen adrenal yang lain, seperti DHEA (dihidroepiandrosteron) dan androstenedion. Sindrom insensititif androgen komplit dan sindrom Swyer merupakan kondisi yang lebih sering di atas, dan keduanya dapat dibedakan secara klinis. Pada sindrom Swyer atau gonadal disgenesis komplit pada pemeriksaan genitalia interna akan ditemukan struktur Mullerian (uterus, tuba Fallopii), streak gonad yang berlokasi di abdomen, dan pada pemeriksaan fisis tidak ditemukan tanda seks sekunder untuk perempuan (payudara tidak tumbuh), serta dalam pemeriksaan hormonal akan ditemukan hipergonadotropik dan hipogonadism. Sedangkan pada Sindrom insensitifitas androgen komplit tidak akan ditemukan struktur Mullerian, gonad ditemukan di luar abdomen (di inguinal atau skrotum), ditemukan pembesaran payudara di usia pubertas, dan kadar testosteron normal atau meningkat. Kelima pasien pada laporan kami menunjukkan hasil pemeriksaan gen SRY positif (Tabel 2 dan 3), meyakinkan keberadaan segmen kromosom $Y$ yang penting dalam pembentukan testis, dan perkembangan sistem reproduksi individu 46,XY. Pemeriksaan lanjutan untuk mendeteksi mutasi pada gen SRY akan mengkonfirmasi diagnosis Sindrom Swyer atau gonadal disgenesis komplit. Kedua kondisi tersebut pada umumnya akan tetap dibesarkan sebagai individu perempuan, sehingga pemeriksaan mutasi gen SRY umumnya tidak diperlukan, bila secara klinis kedua kondisi ini sudah dapat dibedakan. ${ }^{4,8,12}$

Kelemahan penelitian kami ialah pasienGPSR $46, \mathrm{XY}$ yang dirujuk tidak disertai dengan data klinis pasien, seperti derajat genitali ambigu, ada atau tidak testis dengan lokasi testis, dan status pubertas. Namun dari penelitian-penelitian yang sudah pernah dilaporkan, penelitian kami mempunyai jumlah subyek yang relatif sama dan sepanjang pengetahuan kami merupakan penelitian pertama yang membahas cara asuhan jender sebelum diagnosis pada individu GPSR 46,XY. Penelitian yang lain menyampaikan data longitudinal mengenai asuhan jender setelah diagnosis. ${ }^{1,7,8,10,11}$

Sebagai kesimpulan, sebagian besar pasien GPSR 46,XY (45/70) dibesarkan sebagai laki-laki, namun tidak sedikit (22/70) dibesarkan sebagai perempuan. Sebagian besar pasien GPSR 46,XY dirujuk di usia anak dengan genitalia ambigu. Pendekatan seperti yang telah diuraikan dengan mengacu pada pemeriksaan klinis dapat memudahkan klinisi dalam mengarahkan diagnosis kasus GPSR 46,XY, sehingga pemeriksaan lanjutan, tata laksana, dan penentuan jenis kelamin dapat dilakukan dengan lebih baik, meskipun dengan sarana/prasarana yang terbatas.

\section{Daftar pustaka}

1. Uslu R, Öztop D, Özcan Ö, Yilmaz S, Berberoğlu M, Adiyaman P, Çakmak M, Kerimoğlu E, Öcal G. Biopsychosocial variables associated with gender of rearing in children with male pseudohermaphroditism. Turkish J Psychiatry 2007;18:1-10.

2. Lee PA, Houk CP, Ahmed SF, Hughes IA. Consensus statement on management of intersex disorders. Pediatrics 2006;118:e488-e500.

3. Douglas G, Axelrad ME, Brandt ML, Crabtree E, Dietrich J, French S, dkk. Consensus in guidelines for evaluation of DSD by the Texas children's hospital multidisciplinary gender medicine team. Int J Pediatr Endocrinol 2010; 1-17.

4. Allen S. Disorders of Sexual Development. Obstet Gynecol Clin N Am 2009;36:25-35.

5. Marzuki NS, Tridjaja B. Disorders of Sex Development. Dalam: Bidasari Lubis, Muhammad Ali, Gema Nazri Yanni, Yunnie Trisnawati, Oke Rina Ramayani, Lily Irsa, dkk, penyunting. Kumpulan naskah Lengkap PIT IV IKA Medan 2010. Medan: USU Press, 2010. h. 552-69.

6. Gillam LH, Hewitt JK, Warne GL. Ethical principles for the management of infants with disorders of sex development. Horm Res Paediatr 2010;74:412-8.

7. Wisniewski AB, Mazur T. 46,XY DSD with female or ambiguous external genitalia at birth due to androgen insensitivity syndrome, $5 \alpha$-reductase- 2 deficiency, or 17 $\beta$-hydroxyseroid dehydrogenase deficiency: A review of quality of life outcomes. Int J Pediatr Endocrinol 2009: 1-7. 
8. Wisniewski AB, Kirk KD, Copeland KC. Long-term psychosexual development in genetic males affected by disorders of sex development (46,XY DSD) reared male or female. Curr Ped Rev 2008;4:243-9.

9. Jordan BK, Jain M, Natarajan S, Frasier SD, Vilain E. Familial mutation in the testis-determining gene SRY shared by an XY female and her normal father. J Clin Endocrinol Metab 2002;87:3428-32.

10. Reiner WG. Gender identity and sex-of-rearing in children with disorders of sexual differentiation. J Pediatr Endocrinol Metab 2005;18:549-53.
11. Al-Mutair A, Iqbal MA, Sakati N, Ashwal A. Cytogenetic and etiology of ambiguous genitalia in 120 pediatric patients. Ann Saudi Med 2004;24:368-72.

12. Low Y, Hutson JM, Murdoch children research institute sex study group. Rules for clinical diagnosis in babies with ambiguous genitalia. J Pediatr Child Health 2003;39:406-13.

13. Meyer-Bahlburg HFL. Gender assignment and reassignment in 46, XY pseudohermaphroditism and related conditions. J Clin Endocrinol Metab 1999;84:3455-8. 